Western University Scholarship@Western

French Studies Publications

French Studies Department / Département d'études

françaises

2009

\title{
On the Presence versus Absence of Determiners in Malagasy
}

Ileana Paul

The University of Western Ontario, ileana@uwo.ca

Follow this and additional works at: https://ir.lib.uwo.ca/frenchpub

Part of the French and Francophone Language and Literature Commons, and the Syntax Commons

Citation of this paper:

Paul, Ileana, "On the Presence versus Absence of Determiners in Malagasy" (2009). French Studies Publications. 65.

https://ir.lib.uwo.ca/frenchpub/65 


\title{
On the presence versus absence of determiners in Malagasy \\ Ileana Paul \\ University of Western Ontario
}

\begin{abstract}
This article explores definiteness as expressed by the determiner system of Malagasy. In particular, noun phrases with and without an overt determiner are compared in terms of familiarity, uniqueness, and other semantic notions commonly associated with definiteness. It is shown that the determiner does not uniformly signal definiteness (as typically understood) and that bare noun phrases can be interpreted as either definite or indefinite. The determiner instead signals the familiarity of the discourse referent of the DP and the absence of a determiner signals a nonfamiliar DP. In certain syntactic positions, however, where the determiner is either required or banned, the interpretation of DPs is underdetermined.
\end{abstract}

\section{Introduction}

Much of the literature on determiners assumes that they encode (in)definiteness. Lyons (1999) goes so far as to claim that what has been called Determiner Phrase in the literature is in fact a Definiteness Phrase. 
In this article, however, I examine the distribution and interpretation of one determiner in Malagasy, a Western Austronesian language, and show that these data call into question the connection between determiners and definiteness. ${ }^{1}$ This language has what appears to be a dedicated definite determiner (ny) and also licenses bare arguments (noun phrases with no overt determiner). Although traditional descriptions claim the determiner encodes definiteness and that the lack of a determiner encodes indefiniteness, it is possible to show that the standard notions of definiteness (familiarity and uniqueness) cannot account for the full range of data. Instead, the so-called definite determiner only signals the familiarity of the discourse referent, but even this semantic property can be overridden in certain syntactic contexts. In particular, if the determiner is required in a particular position (e.g., the subject position), then the noun phrase can be interpreted as familiar or non-familiar. Similarly, if the determiner is not permitted in a position (e.g., the object of certain prepositions), then the noun phrase can be interpreted as familiar or nonfamiliar. 


\section{Background}

Malagasy is well known for its rather rigid VOS word order and also for the definiteness restriction in the subject position. In particular, traditional grammars and linguistic descriptions claim that the subject must be definite (i.e., it must be a pronoun, a proper name, or a noun phrase headed by a determiner or demonstrative). Hence the contrast in (1): ${ }^{2}$

(1)

a. Lasa ny mpianatra.

gone DET student

'The student(s) left.'

b. *Lasa mpianatra.

gone student

'Some students left.'

(Keenan 1976)

More recently, however, Law (2006) points out that it is possible to find examples where the subject is not definite, despite the presence of the determiner $n y .^{3}$ The examples in (2) and (3) illustrate noun phrases that are headed by the determiner $n y$, but from the translations, the noun phrases are not definite (see section 5 for more conclusive evidence against definiteness). ${ }^{4}$ 
(2) $\mathrm{Ka}$ nandrositra sady nokapohiko ny hazo... then AT.run-away and TT.hit.1SG(GEN) DET tree 'Then I ran away and hit a tree...' $\quad$ (Fugier 1999:17)

(3) Tonga teto ny ankizy anakiray izay. arrive here DET child one DEM 'A (certain) child arrived here.' $\quad$ (Dez 1990:254)

Objects, on the other hand, can either be "bare" (4a) or have a determiner $(4 b) .^{5}$

(4) a. Tia boky frantsay aho.

like book French 1SG(NOM)

'I like French books.'

b. Tia ny boky frantsay aho.

like DET book French 1SG(NOM)

'I like French books.'

(Rajaona 1972:432) 
Note that in this example, the difference in meaning is not obvious, which again calls into question the labelling of $n y$ as a definite determiner-I will return to the difference between (4a) and (4b) in section 7.

Based on these examples, the questions that arise are: first, what is the semantic content of $n y$ ? And second, what happens when $n y$ is absent? Traditional grammars and generative linguists (myself included) have assumed that ny marks definiteness or specificity and that its absence indicates indefiniteness. Based on data such as (2)-(4), the present article questions these assumptions and attempts to find the semantic correlates of determiners in Malagasy.

The organisation of this article is as follows. In section 3, I first provide a basic description of the determiners and demonstratives in Malagasy. Section 4 presents a discussion of definiteness and some of the definitions that have been proposed in the literature. Sections 5 and 6 illustrate the distribution and interpretation of noun phrases with and without a determiner, respectively, and I show the standard definitions of definiteness fail to account for the Malagasy data. Section 7 provides an analysis and section 8 concludes. 


\section{Determiners and their kin in Malagasy}

Before turning to the issue at hand, I provide an overview of the various kinds of determiners and demonstratives found in Malagasy. Traditional grammars list the following determiners:

(5)
a. ra, i, andria, $r y$ - for people
b. ilay-determiner for previously mentioned entities (usually singular)
c. $n y$ - definite/specific determiner (unmarked for number)

(6)

Tonga i Koto / ry Rakoto.
arrive DET Koto / DET Rakoto
'Koto/The Rakoto family arrived.'

(Dez 1990: ex. 21, 29)

Given the head-initial nature of Malagasy, determiners all occur prenominally. The head noun immediately follows the determiner, and other modifiers follow, as schematized in (7) (see Ntelitheos 2006).

NP-internal order:

$\mathrm{DET} / \mathrm{DEM}+\mathrm{N}+\mathrm{POSS}+\mathrm{ADJ}+\mathrm{POSS}+\mathrm{NUM}+\mathrm{Q}+$ relative clause $+\mathrm{DEM}$ 
(8)

a. ny satroka fostin'ny lehilahy
DET hat white'DET man
'the man's white hat'

b. ny alika kely fotsy tsara tarehy anankiray DET dog small white good face one 'one small white pretty dog'

As well as occurring with nouns, determiners can also combine with other categories to create a noun phrase. In (9a), we see the determiner with an adjective, and in (9b) a verb.

a. Nahalala ny tsara sy ny ratsy cause.know DET good and DET bad i Adama sy Eva DET Adam and Eve 'Adam and Eve knew good and evil.'

b. Tsara ny nataony. good DET TT.do.3(GEN)

'What he did was good' (Rahajarizafy 1960:101) 
Ntelitheos (2006) argues that examples such as these are relative clauses, headed by a null $\mathrm{N}$.

Although the focus of this article is determiners, I will briefly mention the demonstrative system. We can see in Table 1, based on RajemisaRaolison (1971:53), that this system is highly complex, encoding six degrees of distance and invisible versus visible.

Table 1: The demonstrative system of Malagasy

\begin{tabular}{lcccc}
\hline & \multicolumn{2}{c}{ Visible } & \multicolumn{2}{c}{ Invisible } \\
No distance & Singular & Plural & Singular & Plural \\
\cline { 2 - 5 } Very close & ito/ity & ireto & izato/izaty & izareto \\
Small distance & io & ireo & izao/izay & izareo \\
Big distance & itsy & iretsy & izatsy & izaretsy \\
Very big distance & iroa & ireroa & izaroa & izareroa \\
Extreme distance & iry & irery & izary & izarery \\
\hline
\end{tabular}

In terms of distribution, demonstratives "frame" the NP-in other words, they appear at the beginning and at the end, much like a phrasal circumfix.
(10) Ento
any io olona ratsy fanahy $\underline{\text { io. }}$
take-away.IMP there DEM person bad spirit DEM
'Take over there this mean person.'

(Rajemisa-Raolison 1971:54)

Certain demonstratives can take on the role of determiners. For example, ireo [visible, plural, undefined distance] acts like the plural counterpart of 
ilay (the determiner for previously mentioned entities) when it appears on its own. Thus ilay, although traditionally unmarked for number, has come to indicate singular.

(11) Tokony hitandrina $\underline{\text { ireo }}$ zaza milalao amin'ny
should AT.be-careful DEM child AT.play P DET
arabe...
street

'The children playing in the street should be careful...'

(Rajemisa-Raolison 1971:54)

Dahl (1951) claims that the determiner $n y$ is historically related to the proximal demonstrative ini that is found in related languages such as Malay. This historical connection between a determiner and demonstratives is very common cross-linguistically_Lyons (1999) claims that definite articles almost always arise from demonstratives. I therefore consider a demonstrative to be a plausible historical source for $n y$.

Before concluding this brief survey of the noun phrase in Malagasy, I note that all quantifier-like elements in Malagasy are positioned after the head noun and after a genitive possessor or adjective. Thus they pattern distributionally with modifiers rather than determiners. In (12), I show the 
position of rehetra 'all' and sasany 'some' (examples adapted from Keenan 2007).

(12) a. Hitako ny tranon-dRabe rehetra
TT.see.1SG(GEN) DET house.GEN.Rabe all
'I saw all Rabe's houses.'
b. Novangiako ny zazakely marary rehetra
TT.visit.1SG(GEN) DET child sick all
'I visited all the sick children.'
c. Efa lasa ny mpianatra sasany.
already gone DET student some
'Some of the students have already left.'

The above data show that Malagasy has dedicated determiner-like elements that appear in a fixed position (prenominal) within the noun phrase. In the next section, I provide an overview of determiners in general, and their semantic and syntactic roles. In sections 5 and 6, I return to the Malagasy determiner $n y$ and discuss it in more detail (I will focus on this determiner and leave the other determiners and the demonstratives for future research). 


\section{What are determiners?}

Determiners are commonly assumed to play two key syntactic and semantic roles: as the head of noun phrase and as the indicator of definiteness. The goal of this section is to describe some of the definitions of definiteness that have been proposed in the literature. In subsequent sections, I explore how Malagasy fits with the standard definitions.

As noted in the introduction to this volume, many syntacticians analyse nominal arguments as DPs rather than NPs. That is, noun phrases are in fact projections of the head D (for determiner), whose complement is NP. This line of thinking typically assumes that the determiner turns an NP into an argument, in other words, into something that the syntax can manipulate. Along with this syntactic analysis is a semantic parallel: nouns (and noun phrases) are considered to be predicates, type $<\mathrm{e}, \mathrm{t}>$, and the addition of a determiner creates an entity, type e.

As also noted in the introduction, determiners are typically taken to encode (in)definiteness. Definiteness has long been discussed in both the linguistic and philosophical literature and remains the subject of much debate. I limit myself here to a very brief overview of some of the recurring themes that arise in analyses of definiteness, following closely 
the description in Lyons (1999). Simplifying his discussion, definiteness can be seen to indicate either familiarity or uniqueness (or both). Lyons uses "identifiability" rather than familiarity, but the two notions are similar, and he defines it as follows:

Familiarity/Identifiability:

The use of the definite article directs the hearer to the referent of the noun phrase by signaling that he [the hearer] is in a position to identify it. (Lyons 1999:5-6)

Uniqueness ("inclusiveness" for Lyons) can be described as:

\section{Uniqueness/Inclusiveness:}

The reference is to the totality of the objects or mass in the context which satisfy the description. (Lyons 1999: 11)

As Lyons points out, some uses of the definite determiner in English show familiarity (and not uniqueness), while others show uniqueness (but not familiarity). $\mathrm{He}$ nevertheless proposes that definiteness is the grammaticalization of familiarity and can develop other uses (as is typical with grammatical categories). ${ }^{6}$ 
A third notion that has been connected to definiteness and determiners is domain restriction (Westerståhl 1984; von Fintel 1999, inter alia). It is well known that quantifiers typically do not quantify over the entire domain (the world), but rather are sensitive to the context. For example, in (15), every freshman is not used to refer to all the freshmen in the world, but instead to the freshmen in a contextually relevant domain.

(15) Every freshman is from out of state. (von Fintel 1999:3)

This is also true for other DPs, such as the freshmen, and Westerståhl (1984) claims that the determiner the is itself domain restriction. Gillon (2006, this volume) develops this line of analysis and argues that determiners in Salish introduce domain restriction and that they are associated with implicature of uniqueness; in English, on the other hand, the introduces domain restriction, but in addition, it asserts uniqueness. Moreover, she claims that familiarity can be derived from domain restriction plus the uniqueness assertion (in English). In fact, one of Gillon's central claims is that cross-linguistically determiners always introduce domain restriction.

Taking the above discussion as our guide, we can ask whether determiners in Malagasy play a key role in creating arguments from predicates, whether they encode definiteness (familiarity, uniqueness, 
domain restriction), and whether their absence signals indefiniteness. I should point out here that Massam, Gorrie and Kelner (2006) explore the Niuean determiner system and show that no one group of morphemes in this language plays the role of determiner, as we understand it. Instead, the case+article particles are the top-level category within noun phrase that ensures referentiality or argumenthood, while the quantifiers encode notions such as backgrounding and focus, rather than definiteness. Thus any study of determiner-like elements in a particular language must be open to the presence of novel meanings and uses, as well as languagespecific division of labour.

I show in the next section that the Malagasy determiner ny does not encode uniqueness but it does presuppose familiarity. 


\section{Malagasy determiners}

This section explores the Malagasy determiner $n y$, in particular its semantics. The properties of the other determiners (in particular, the determiner ilay) and the demonstratives await further research. To avoid confusion, I will refer to noun phrases that have the determiner as DPs and those without as bare nominals. Whether bare nominals are headed by a null $\mathrm{D}^{\circ}$ or are in fact D-less (i.e., NPs) is an issue I turn to directly.

\subsection{Syntax}

Is the determiner required for argumenthood in Malagasy? We have already seen that arguments do not need to have a determiner, and I provide more examples in (16), where the complements of the verbs are bare nominals.

(16) a. Manolotra penina izy.

AT.offer pen $3(\mathrm{NOM})$

'She offers a pen.' 


\section{b. Rakofana kopy ny tsaramaso. \\ TT.cover cup DET bean}

'The beans are covered with a cup.'

I argue that bare nominals are headed by a null determiner; in other words, Malagasy does not permit NP arguments.

In the syntactic literature, null heads are often analysed as elements that need to be licensed in some particular way. For example, null complementizers have a limited distribution and therefore are argued to have special licensing requirements. As is well known, the complementizer in English is obligatory in sentential subjects.

(17) a. People widely assume (that) politics is corrupting.

b. *(That) politics is corrupting is widely assumed.

Whether this licensing is via government or some other means (e.g., Landau 2007 claims that the Extended Projection Principle (EPP) is a PF constraint that requires the head-here $\mathrm{C}^{\circ}$ - to be overtly realised), the generalization appears to be true. Similarly, the restricted distribution of so-called bare nouns in Romance languages has been linked to the licensing requirements of the null determiner (Contreras 1986). With this background in mind, I now turn to the Malagasy data. 
First recall that bare nominals in Malagasy (DPs without a determiner or demonstrative) are rather limited in distribution in Malagasy. As discussed by Keenan (1976), they are barred from the subject position and, moreover, they are usually absent in positions marked by genitive case (e.g., the non-active agent and the complement to certain prepositions). They are therefore acceptable in three positions: direct object (18a), predicate (18b), accusative object of a preposition (18c). ${ }^{7}$

a. Mividy boky aho.

buy book $1 \mathrm{SG}$ (NOM)

'I am buying a book/books.'

b. Vorona ny goaika

bird DET crow

'The crow is a bird.'

c. Ampirimo ao an'efitra ny kitaponao.

put-away there P room DET bag.2SG

'Put your bag away in the room.'

As a second restriction, bare nominals (unlike DPs) are not permitted in displaced positions. For example, bare nominal objects cannot 
scramble: in (19) the DP ny ankizy 'the children' can scramble rightwards past the adverb matetika 'often', while in (20), scrambling of the bare nominal ankizy 'children' is impossible (Rackowski 1998; Rackowski and Travis 2000).

a. Mamitaka ny ankizy matetika Rabe.

AT.trick DET child often Rabe

'Rabe often tricks the children.'

b. Mamitaka matetika ny ankizy Rabe.

AT.trick often DET child Rabe

'Rabe often tricks the children.'

(20) a. Mamitaka ankizy matetika Rabe.

AT.trick child often Rabe

'Rabe often tricks children.'

b. * Mamitaka matetika ankizy Rabe.

AT.trick often child Rabe 
This restriction on movement also rules out bare nominals from appearing in the topic position, as in (21a):

a. *Bibilava dia mikisaka.

snake TOP AT.crawl

'Snakes crawl.'

b. Bibilava no mikisaka.

snake FOC AT.crawl

'It is snakes that crawl.'

Bare nominals can appear in the focus position (21b), but it has been argued that this is in fact not an instance of focus movement - the bare nominal is in fact the matrix predicate (Paul 2001). And we have already seen that predicates (not surprisingly) can be bare (see (18b)).

Thus the distribution of bare nominals is not free, much like the distribution of sentential subjects without the complementizer. Generalizing from this restricted distribution, I conclude that bare nominals are not truly bare: there is a null determiner, and it is this null determiner that limits the distribution of the DP. ${ }^{8}$ Moreover, determiners are not permitted in the predicate position (with some minor exceptions). 
Therefore the data suggest that in Malagasy, truly bare nominals are predicates (and therefore are NPs). In order to act as an argument, a noun must combine with a determiner (null or overt). We now turn to the semantics of the overt determiner-I will discuss the null determiner in section 6 .

\section{2. $\mathrm{Ny}$}

This section focuses on the determiner $n y$ and its interpretation. I present data from DPs in different syntactic positions: subject, object of preposition, and direct object. We will see that the interpretation of $n y$ appears to depend on its position in the clause.

\subsubsection{Subjects}

As mentioned earlier, $n y$ is usually described as a specific or definite determiner, one that can also appear with generics, as in (22).

\section{(22) Biby ny alika.}

animal DET dog

'The dog is an animal.' (Domenichini-Ramiaramanana 1977) 
Many examples show familiar and unique readings (i.e., "definite) for DP subjects. For example, the following sentence comes immediately after a context where the travellers are putting their bags into a canoe. Thus the DP ny lakana 'the canoe' in (23) is both familiar (previously mentioned) and unique (there is only one canoe in the context).

(23) Nisosa mora teny ambony rano ny lakana. AT.go-forward easy there on water DET canoe 'The canoe went gently forward on the water.' (Ravololomanga 1996: 14)

But we have already seen that the determiner doesn't always mark uniqueness or familiarity. Let us consider the following textual example, repeated from (2):

$\begin{array}{ccccc}\text { Ka } & \text { nandrositra } & \text { sady } & \text { nokapohiko } & \text { ny hazo... } \\ \text { then } & \text { AT.run-away } & \text { and } & \text { TT.hit.1SG(GEN) } & \text { DET tree }\end{array}$

'Then I ran away and hit a tree...'

(Fugier 1999:17)

Fugier claims that the referent of ny hazo 'the tree' is neither familiar (it need not be a tree that is salient in the discourse or context) nor is it unique (there could have been several trees). In other words, in (24) we have an example of a discourse-new argument headed by $n y$. Similarly, in the 
following example, the response in (25b) has a determiner, but the DP can be interpreted as indefinite (it doesn't necessarily mean 'I sold the five').

a. Firy ny vorom-bazaha lafonao?

how.many DET bird-foreigner sold.2(GEN)

'How many ducks did you sell?'

b. Lafo ny dimy.

sold DET five

'I sold five.'

(Dez 1980:183)

(lit. 'The five were sold.') $)^{9}$

The response in $(25 b)$ is possible in a context where the person had ten ducks and sold an unspecified group of five (it is also possible in a context where there were only five ducks in total). Thus the referent of ny dimy 'the five' is not necessarily unique, but it does appear to be familiar (it refers to a subset of the ducks previously introduced). As we see in (25) and will see in several subsequent examples, if a referent is introduced into the discourse, a DP must refer to that referent (often giving rise to a partitive reading). 


\subsubsection{Objects of prepositions}

Let us now look at DPs that are the object of a preposition - in particular, the preposition amin, which typically occurs with a DP. ${ }^{10}$ Once again, we see that the interpretation may be familiar and unique. The following sentence comes from a story called "The blue lake", and the lake in question has already been mentioned in the text:

$$
\begin{aligned}
& \text {... tonga teo amin'ny farihy manga. } \\
& \text { arrive there P DET lake blue } \\
& \text { '... (they) arrived at the blue lake.' }
\end{aligned}
$$

(Ravololomanga 1996:56)

But as with subjects, a DP in this position may also be interpreted as indefinite. This effect is illustrated in the following example, where the DP ny sotro mahamay 'the hot spoon' is the complement of the preposition amin . 


$$
\begin{aligned}
& \text { (27) ...misy mpampiasa karany iray nandoro ny tava } \\
& \text { exist employer Pakistani one AT.burn DET face } \\
& \text { sy ny fen'ny mpiasany tamin'ny sotro } \\
& \text { and DET thigh DET worker.3(GEN) with'DET spoon } \\
& \text { mahamay. }
\end{aligned}
$$

hot

'... there is an Indo-Pakistani employer who burned his servant's face and thigh with a hot spoon.'

(Jedele \& Randrianarivelo 1988:20)

\begin{abstract}
Again, the referent of this DP is neither familiar nor unique-the spoon has not been mentioned previously nor is it referred to again in the text. If there is a previously introduced DP in the discourse, however, the DP must refer back to it. Thus in (28), the DP in the second sentence is interpreted as partitive.
\end{abstract}

(28) Niditra ny vehivavy telo. Niresaka tamin'ny vehivavy

AT.enter DET woman three AT.talk with DET woman iray aho.

one $1 \mathrm{SG}(\mathrm{NOM})$

'Three women entered. I talked with one of the women.' 
Thus we see that DPs (when the grammatical subject or the object of a preposition) need not be familiar nor unique. But if a referent is in the discourse, the DP must be interpreted as part or all of that referent, that is, as familiar.

\subsubsection{Direct objects}

Turning to the object position, all of the textual examples I have found of DPs are both familiar and unique. For example, ny lefona 'the spears' in the following sentence was introduced in a previous paragraph.

... nitoraka ny lefona avy lavitra.

AT.throw DET spear come far

'... (they) threw the spears from afar.'

(Ravololomanga 1996:38)

I have not been able to find textual examples of discourse-initial, nonfamiliar arguments that are headed by $n y .{ }^{11}$ When I construct such examples and ask speakers if they are acceptable at the beginning of a story or discourse, they reject them. 
a. Nisy mpanjaka nanorina ny lapa.

exist king build DET palace

'There was a king who built the palace.'

b. Inona no vaovao? Nividy ny trano aho.

what FOC new buy DET house 1SG(NOM)

'What's new? I bought the house.'

Thus (30a) is only appropriate when the palace has been introduced, and the discourse in (30b) is only acceptable in a context where the house has already been discussed. In other words, DP objects must be familiar. On the other hand, it is easy to create situations that show that DPs in object position are not always unique. For example, in (31) ny akondro does not mean 'the bananas', but rather 'some of the bananas', a partitive reading. ${ }^{12}$ 


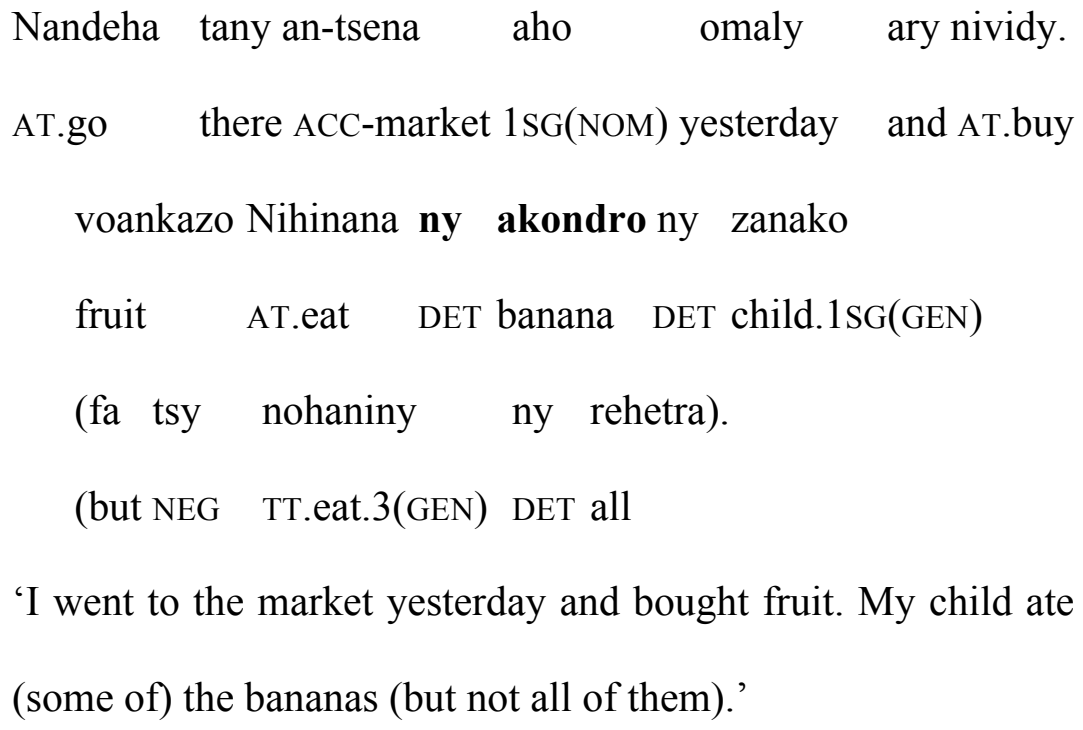

'I went to the market yesterday and bought fruit. My child ate (some of) the bananas (but not all of them).'

Thus DP objects must be familiar, as seen in (30), but they are not always associated with uniqueness, as we see in (31). I now turn to the scopal properties of DPs.

\subsubsection{Scope}

In a recent discussion of the so-called definiteness restriction on subjects, Keenan (2008) claims that subjects are only "definite" in that they presuppose existence and therefore always scope over negation.

(32) Tsy nandeha tany an-tsekoly ny mpianatra telo. NEG AT.go there ACC-school DET student three 'Three students didn't go to school.'

* 'It is not the case that three students went to school.' 
Keenan shows that subjects take wide scope even when apparently indefinite (not previously mentioned, not an identified group). In (32), for example, the judgment is that the speaker is merely making a claim about some three students; these students need not be under discussion.

I should point out here that $n y$ doesn't uniquely mark wide scope- - the wide scope likely comes from the high structural position of the subject. As shown in (33), DP objects can take narrow scope.

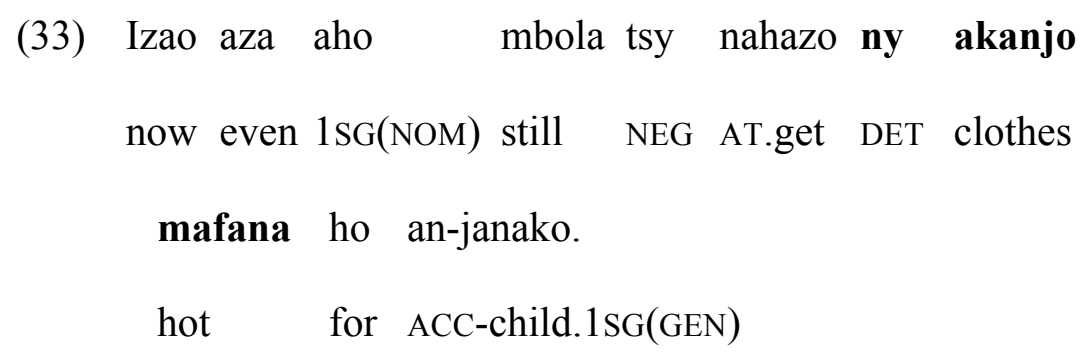

'Even now I still haven't gotten (any) warm clothing for my child.' $\quad$ (Jedele \& Randrianarivelo 1988:132)

From the context (and from native-speaker judgments), it is clear in (33) that negation scopes over the object. ${ }^{13}$ Wide scope is of course possible, as seen in (34), where the object scopes over the adverb. 
(34) Mamaky ny boky roa lalandava Rabe.

AT.read DET book two always Rabe

'Rabe always reads two books.' (the same two books)

Summing up, the determiner $n y$ in Malagasy does not always indicate definiteness - in particular, DPs are not always unique nor familiar. The interpretation appears to depend on the syntactic position-subjects and objects of prepositions (where ny is obligatory) allow non-familiar, nonunique readings, while DP objects are familiar (but not necessarily unique). Moreover, although subjects take wide scope, wide scope is more likely a result of the position of subjects, rather than a property of the determiner. Outside of the subject position, DPs can take either wide or narrow scope.

\subsection{Demonstratives}

I return to demonstratives briefly, only because there are some demonstratives in Malagasy that can be used as determiners. Demonstratives are typically definite and also encode deixis (spatiotemporal context). As mentioned earlier, Malagasy demonstratives normally frame the NP, but certain ones can also be used in a determiner- 
like fashion (no framing). In these cases, even demonstratives can receive an indefinite interpretation, as seen in (35).

... mahasarika azy kokoa ny maka sary ireo CAUSE.attract 3(ACC) most DET take picture DEM olona eo amin'ny fianinana andavan'andro. person there PDET life everyday '... he is most interested in photographing people in daily life.' (Jedele \& Randrianarivelo 1988:14)

As is clear from the translation and from native speaker judgements, the meaning is simply 'people', not 'these people' or even 'the people'. The indefinite reading of demonstratives appears to be limited to uses of ireo as a plural determiner.

A related use of demonstratives as indefinites can be seen in the following example, where the clausal subject is framed by the demonstrative ity 'this': 
... zary fidiram-bola ho an'ny olo-marobe teny

become source-money for ACC DET person-many there amin'iny faritr' i Manandriana-Avaradrano iny

P DEM area DET Manandriana-Avaradrano DEM

ity fakana tany hosivanina any anaty rano ity

DEM taking earth TT.sieve there in water DEM

'... taking soil to sieve it in water has become a source of income for a great many people in the Manandriana-Avaradrano area...' (Jedele \& Randrianarivelo 1988:53)

This example is from the first sentence of a newspaper article about people looking for gold, so it provides the first mention of stealing dirt. This use of ity is cataphoric - it introduces a new entity that will be important in the remainder of the article. Note that colloquial English this has a similar use (Prince 1981). I set the study and analysis of demonstratives aside for future research.

\section{The absence of determiners}

In the preceding section, we saw that the presence of the determiner $n y$ does not consistently signal a definite interpretation. We can now ask the 
opposite question: does the absence of ny consistently mark indefiniteness? In other words, is the null determiner indefinite? What I show in this section is that a bare nominal can be interpreted as definite or indefinite. Thus neither the presence nor the absence of determiners is strictly correlated with definiteness. As I did above, I begin by looking at the two positions where bare nominals occur: as the object of certain prepositions and direct object.

\subsection{Object of preposition}

In looking through texts, I have found many examples of a bare nominal that is the object of a preposition referring to a previously identified or contextually salient entity. ${ }^{14}$ One example is from a newspaper article about people sieving for gold. In the first clause, locked houses are mentioned (with a determiner); in the second clause the author refers to the same houses with a bare nominal. 
(37) Lalina aza fa ny tranon'olona mihidy mihitsy no nisy deep even C DET house person AT.lock indeed FOC exist namoha, ka alain'dry zalahy ny tany ao AT.open and TT.take.DET 2PL DET earth there anaty trano in house 'Even more seriously, locked houses had people breaking in; the scoundrels took the soil from inside the houses...' (Jedele \& Randrianarivelo 1988:53)

In fact, looking through texts, it appears that the complement of the preposition anaty 'in' is typically a bare nominal, even if the referent of that noun is familiar or unique. ${ }^{15}$ The following sentence is from a story about two brothers who arrive at a lake, go up to the edge of the water and make a lot of noise. 


Voatabataba ny lalomena mpiandry farihy ka
PASS.noise DET lalomena ${ }^{16}$ guardian lake and
nisafaoka avy tany anaty rano lalina tany.
rise.up come there in water deep there
'The lalomena, guardian of the lake, was disturbed and rose up
from the deep water.' (Rajaobelina 1960, page numbers
unavailable)

Here anaty 'in' is followed by rano 'water', a bare nominal despite being familiar (the previous sentences have mentioned the lake and the water) and unique. ${ }^{17}$ Of course, a bare nominal can also be indefinite (unfamiliar, not unique - the following sentence is from the beginning of a story about four friends: Vo, Vy, Tro, and Lalo.

(39) Nitoetra tao anaty farihy avara-tanàna kosa i Tro.
AT.live there in lake north-town as.for i Tro.
'Tro lived in a lake north of the town.' (Rajaobelina 1960)

Here the lake is new in the discourse.

Elicited examples show the same effect: the object of anaty is typically bare and can be interpreted as familiar: 
Nandeha tany an-tsena aho ary nividy harona telo. AT.go there ACC-market $1 \mathrm{SG}(\mathrm{NOM})$ and AT.buy basket three Nametraka boky tao anaty harona aho.

AT.put book there in basket $1 \mathrm{SG}(\mathrm{NOM})$

'I went to the market and bought three baskets. I put books in the baskets.'

The bare nominal harona 'basket' in the second sentence of (40) can be understood as referring to the baskets that I bought at the market.

Thus Malagasy has two types of prepositions: ones that almost always select a DP (e.g., amin) and ones that almost always select a bare nominal (e.g., anaty). (In this way, the prepositions differ from the subject position, where bare nominals are prohibited.) In both cases, the noun phrase in question can be interpreted as familiar or nonfamiliar. As we will see in the next section, the familiar interpretation of bare nominals is not available in direct object position.

\subsection{Direct objects}

As mentioned in section 2, direct objects in Malagasy can appear either with or without a determiner. Example (41), repeated from (4), shows the direct object as a bare nominal in (a) and a DP in (b). 
a. Tia boky frantsay aho.

like book French $1 \mathrm{SG}(\mathrm{NOM})$

'I like French books.'

b. Tia ny boky frantsay aho.

like DET book French 1SG(NOM)

'I like French books.'

(Rajaona 1972:432)

Rajaona's discussion of these examples does not immediately make clear what the difference in interpretation is. Looking at bare nominal objects in context, however, we see they are consistently non-familiar.

One potential counter-example comes from a newspaper article about cyclones: from the context (and the translation provided) it was all the streets that were blocked, but arabe 'street' is bare.

$$
\begin{aligned}
& \text {... sy nanapaka arabe mihitsy tany amin'io toerana } \\
& \text { and AT.cut street absolutely there P DEM place } \\
& \text { io ... } \\
& \text { DEM }
\end{aligned}
$$

'... and completely blocked the streets there in that area...'

(Jedele \& Randrianarivelo 1988:33) 
The apparently definite interpretation of arabe 'street' may, however, be a result of mihitsy 'completely' acting like an adverbial quantifier, binding the bare noun.

Working with speakers, however, it is clear that bare nouns cannot be used to refer to entities that have been mentioned in the preceding discourse. ${ }^{18}$ For example, the bare nominal mananasy 'pineapple' in (43b) cannot be used refer back to the previously mentioned pineapple in (43a).

a. Nahita mananasy naniry tery an-tsefatsefa-bato ilay find pineapple grow there P-broken-rock DEF zazavavy.

girl

'The girl found a pineapple growing in the talus.'

b. \# Nandeha nanapaka mananasy izy. go take pineapple $3(\mathrm{NOM})$ 'She went to get a pineapple.'

Similarly in (44b), the second mention of sifaka (a kind of lemur) is to a new group, not the four mentioned in (44a) - a partitive reading is not possible. 
(44)

a. Nandeha tany an-ala aho omaly ary AT.go PST.there P-forest 1SG(NOM) yesterday and nahita sifaka efatra. AT.see lemur four 'I went to the forest yesterday and saw four lemurs.'

b. \# Nanaraka sifaka aho.

AT.follow lemur 1SG(NOM)

'I followed lemurs.'

If the noun itself is not mentioned, but is contextually salient, it is still not appropriate to use a bare nominal. For example, consider a context where I have lost my chicken and my neighbour knows this and utters the sentence in (45):

$\begin{array}{lll}\text { Nahita akoho aho } & \text { tamin'ny } & \text { alina. } \\ \text { AT.see chicken } 1 \mathrm{SG}(\mathrm{NOM}) & \text { P DET night } \\ \text { 'I saw a chicken last night.' } & \end{array}$

The sentence in (45) is interpreted just like the English translation: my neighbour is simply telling me that she saw a chicken. It may turn out to 
be mine, but she is not in a position to say that it is. Summing up, the data show bare nominal direct objects to be non-familiar.

\subsection{Body parts}

I now mention some special instances of bare nominals that are clearly interpreted as unique, but we will see that these are a special case. Keenan and Ralalaoherivony (2000) discuss possessor raising in Malagasy, a very productive phenomenon where a body part (or other inalienable possession) surfaces as a bare nominal, such as nify 'tooth' in (46a) and kibo 'belly' in (46b).

a. Fotsy nify Rabe.

white tooth Rabe

(lit. 'Rabe is white tooth.')

'Rabe has white teeth.'

b. Marary kibo aho.

sick belly $1 \mathrm{SG}(\mathrm{NOM})$

(lit. 'I am sick belly.')

'I am sick in the stomach.'

(Keenan \& Ralalaoherivony 2000: ex, 4a) 
As is clear from these examples, the bare noun is semantically definite-in particular these examples show uniqueness. The sentence in (46a) means that all of Rabe's teeth are white, not one or some (it would be false if he had some teeth that were not white). Not surprisingly, these bare nouns can scope over negation (as we will see below, this is unlike other bare nominals in Malagasy, which scope low):

(47) Tsy maty filoha ny firenana. Sitrana izy.
NEG dead president DET country cured 3(NOM)
'The country's president didn't die. She is cured.'

I set aside possessor raising here, given that the semantics of the bare nouns in this context arises from semantics of the construction as a whole (see Paul 2009 for some discussion).

\subsection{Scope}

When looking at examples with scope-bearing elements, bare nominals in Malagasy can take either narrow or wide scope, unlike (for example) bare plurals in English. We can see this variable scope in (48), where the bare 
noun alika 'dog' can either scope under the verb mitady 'to look for', as in (48a) or it can take wide scope, as in (48b).

a. Mitady $\quad$ alika aho - na alika inona
AT.look-for $\operatorname{dog} 1 \mathrm{SG}(\mathrm{NOM})$ or dog what
na alika inona.
or dog what

'I'm looking for a dog - any dog.'

b. Mitady alika aho - kely sy mainty

AT.look-for dog $1 \mathrm{SG}(\mathrm{NOM})$ small and black

ilay izy.

DEF 3(NOM)

'I'm looking for a dog - it's small and black.'

Similarly, in (49), we can see the variable scope of the bare noun boky 'book' with respect to the modal tokony 'should'.

a. Tokony hamaky boky ianao-

should FUT.AT.read book 2SG(NOM) -

na boky inona na boky inona.

or book what or book what

'You should read a book — any book.' 


b. Tokony hamaky boky ianao -
should FUT.AT.read book 2SG(NOM) -
"farihy manga" ny anarany.
lake blue $\quad$ DET name.3(GEN)
'You should read a book - "Blue Lake" is its title.'

Bare nominals can also scope over negation: in (50a), we see that a bare nominal in the scope of negation introduces a discourse referent that can be referred to later by a pronoun (cf. (47)); (50b) shows a similar effect with a [+human] noun.

a. Tsy namaky boky Rasoa. Sarotra loatra NEG AT.read book Rasoa difficult too ilay izy. DEF $3(\mathrm{NOM})$

'Rasoa didn't read a book. It was too difficult.' 


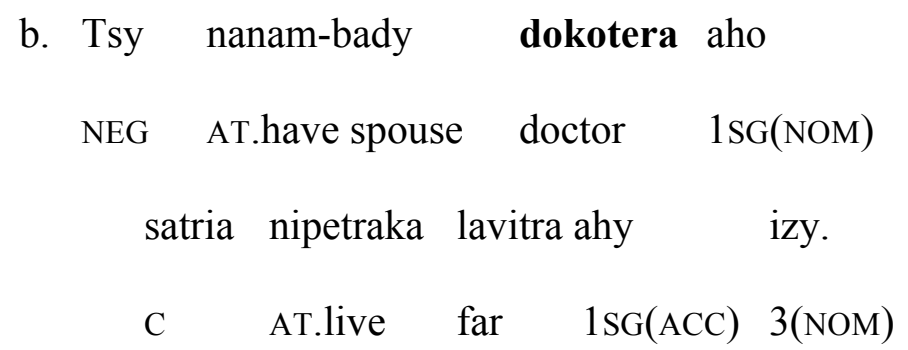

'I didn't marry a doctor because he lived too far from me.'

Thus as far as scope is concerned, bare nominal direct objects in Malagasy behave like indefinites.

\subsection{Summary}

This section has provided an overview of the distribution and interpretation of the lack of the determiner, and it appears that the absence of a determiner does not always signal indefiniteness. Instead, bare nominals can be interpreted as either definite or indefinite. But such flexible interpretation is limited to positions where the bare nominal is required (e.g., the complement of anaty 'in') - otherwise bare nominals are interpreted as non-familiar. These results fit with what we saw in section 5 , where nouns headed by determiners can also be interpreted as either definite or indefinite. The syntax requires determiners in certain positions (e.g., the subject) and bars them in others, but even in contexts 
where determiners have a freer distribution (e.g., the object), we can see both definite and indefinite readings of bare nouns.

\section{Discussion and Conclusion}

In this section, I consider the Malagasy data from a broader perspective and look at mismatches between form and meaning in other languages.

\subsection{Comparisons with English}

At first glance, the Malagasy facts look similar to the English data discussed by Stvan (1998) and Carlson and Sussman (2005). In particular, Stvan analyses bare singular count nouns that show up in "unexpected" positions, such as those in (51).

(51) a. School is not in session.

b. I've left town.

c. She spent time in prison. 
In these cases, the bare noun can be interpreted as definite, much like we have seen with certain examples in Malagasy. Carlson and Sussman (2005) examine so-called indefinite definites:
a. Sandy went to the store.
b. I'll read the newspaper.

They show that these apparent definites can have a weak/indefinite reading, again similar to what we saw for subjects in Malagasy.

It would nevertheless be a mistake to draw too close a connection between the English and Malagasy data. In particular, the English examples are well known to be limited in distribution. Only certain nouns are permitted in the bare singular count noun cases, and only certain verbs and prepositions license bare nouns. Indefinite definites are similarly lexically and positionally restricted. In Malagasy, on the other hand, any noun can be bare and any noun can be in a DP in the subject position. Moreover, unlike the English bare singular nouns in (51), bare nominals in Malagasy may be modified freely.

There are, however. Malagasy examples that are similar to the English bare singulars; that is, bare nominals in direct object position that get a familiar interpretation. Like the English data, these appear to be lexically 
restricted: while kintana 'star' (53a) and volana 'moon' (53b) are possible, filoha 'president' can only receive a non-familiar interpretation (53c).

a. Nijery kintana aho tamin'ny alina.

AT.watch star 1SG(NOM) P'DET night

'I looked at the stars last night.'

b. Nahita volana aho tamin'ny alina.

AT.see moon 1SG(NOM) P DET night

'I saw the moon last night.'

c. ?? Nahita filoha aho.

AT.see president $1 \mathrm{SG}(\mathrm{NOM})$

'I saw a president.'

$\neq$ 'I saw the president.'

Recall the possessor raising data, which also are lexically restricted. Thus the English data and the Malagasy data in (53) appear to merit a construction-specific analysis, while the Malagasy data that have been the focus of this article are more systematic and require a different analysis. 


\subsection{Effability}

The analysis of the Malagasy determiner $n y$ that I propose is that it uniformly encodes familiarity. Familiarity accounts for the fact that if there is a relevant discourse referent present, then the DP must refer back to that referent, typically giving rise to a partitive reading. The zero determiner, however, is not associated with familiarity. Hence, in cases where a relevant discourse referent is accessible, coreference is not possible. Instead, a bare nominal in such a context is interpreted as nonfamiliar (new).

We have seen, however, that not all DPs are interpreted as familiar and that not all bare nominals are non-familiar. What I suggest here is that in cases where the overt determiner is required (e.g., the subject position), other factors influence the interpretation. And similar effects occur when the zero determiner is required (e.g., the object of anaty). In particular, I adapt an analysis proposed by Adger (1996) that draws on notions of economy and effability. His analysis can be implemented as follows: given that there is no convergent derivation where a bare nominal surfaces in the subject position, a DP subject can be interpreted as either familiar or non-familiar. Alternatively, the Malagasy data could be an instance of blocking (Williams 1997): if there are two forms, they must have different meanings; if there is only one form, it is permitted to be ambiguous. ${ }^{19}$ 
Although familiarity is most clearly seen in sentences where there is a clear linguistic context, the familiarity of $n y$ also shows up when speakers try to express the difference between sentences with and without this determiner in "out of the blue" contexts. Consider again Rajaona's examples, repeated again from (4):

a. Tia boky frantsay aho.

like book French $1 \mathrm{SG}(\mathrm{NOM})$

'I like French books.'

Rajaona's comment: "valeur généralisante” (generalizing value - my translation)

b. Tia ny boky frantsay aho.

like DET book French 1SG(NOM)

'I like French books.'

Rajaona's comment: "valeur catégorisante (la catégorie de livres qui sont écrits en français—par opposition implicite aux livres non écrits en français)" (categorizing value (the category of books written in French-as implicitly opposed to books not written in French - my translation) (Rajaona 1972:432)

In his translation, Rajaona notes that when the determiner is present there is an implicit opposition with other kinds of books, non-French books. In 
other words, the determiner signals the presence of a familiar entity (the set of books). I have found a similar effect in the following pair:

a. Fotsy ny volon'akoho.

white DET hair chicken

'Chicken feathers are white.'

$=$ Generic statement about chicken feathers

b. Fotsy ny volon'ny akoho.

white DET hair DET chicken

(i) 'Chicken feathers are white.'

$=$ Generic, but in context of talking about the coats of various animals

(ii) 'The chicken's feathers are white.'

$=$ Statement about a particular chicken

In (56b-i), the determiner signals that chicken feathers are being discussed, not the feathers (or coat) of any other animal. Again, there is a familiar set (all animals) that is presupposed.

\subsection{Conclusion}


In sum, according to traditional descriptions the Malagasy determiner $n y$ is a definite determiner, and the absence of ny signals indefiniteness. Looking at a range of examples, however, we have seen there is no apparent correlation between the presence of $n y$ and definiteness as traditionally understood. For example, we have seen several examples of subject DPs that are indefinite (not unique, not familiar). At this point, one might be tempted to conclude that there is no systematic semantic interpretation associated with $n y$. Looking closely at texts and at the interpretation of DPs in context, however, I have shown that $n y$ is always used for familiar DPs and that bare nominals are always non-familiar. The exceptions can be explained by blocking: where a determiner is obligatory or prohibited, both familiar and non-familiar readings are permitted.

The Malagasy facts bear some similarity to the Skww $\underline{x} w u ́ 7 m e s h$ data discussed by Gillon (2006, this volume). The crucial difference is that in Malagasy DPs are not felicitous in novel contexts, unlike Skwxwú7mesh DPs. Thus, unlike Skwxwú7mesh determiners, Malagasy ny asserts familiarity. One consequence of this difference is that while for Gillon familiarity is a derived notion (arising from uniqueness plus domain restriction in English), for me it is a primitive. On the other hand, the Malagasy data are not amenable to the analysis proposed by Mathieu (this volume) for Old French, where determiners do not encode any aspect of definiteness (e.g., familiarity, uniqueness), but instead mark focus (or are 
used for prosodic purposes). As mentioned above, although the data initially suggest that determiners in Malagasy are not related to the traditional notion of definiteness at all, a more careful study of their distribution and interpretation indicates that once certain position facts are taken into account, ny can be shown to correlate with familiarity (and its absence with non-familiarity). Thus definiteness, understood as combining uniqueness and familiarity, is not a universal feature of determiners. As a final note, Lyons (1999) suggests that the core of definiteness is familiarity; the data in this article support his claim.

\section{Acknowledgements}

This article would not have been possible without the help of Rita Hanitramalala, Dina Rakoto-Ramambason, Hary Ramanarivo, Vololona Rasolofoson, Francine Razafimboaka, and Martelline Razafindravola. I would like to thank audiences at the University of Western Ontario, at the Determiners Workshop (Winnipeg, 2006), and at the Determiners and Classifiers workshop at the University of Toronto, in particular Jila Ghomeshi, Martina Wiltschko, Éric Mathieu, and Peter Hallman, for their comments and suggestions. Thanks also to Eric Potsdam and Lisa Matthewson for their input and to two anonymous reviewers for their very 
helpful feedback. Any errors remain my own. This research was partially funded by the Canada Research Chair program and by a standard research grant from the Social Sciences and Humanities Research Council of Canada (410-2005-1758).

\section{Notes}

${ }^{1}$ I am by no means the first linguist to question this connection. See for example Matthewson (1998) and Gillon (2006, this volume).

${ }^{2}$ Unless otherwise indicated, all Malagasy data are from my own notes.

Nouns in Malagasy are number neutral—plural marking is only overt in the demonstrative system.

The following abbreviations are used: 


\begin{tabular}{llll}
\hline 1 & first person & FOC & focus \\
2 & second person & GEN & genitive \\
3 & third person & NOM & nominative \\
ACC & accusative & NUM & numeral \\
ADJ & adjective & P & preposition \\
AT & actor topic & PL & plural \\
CT & circumstantial topic & POSS & possessor \\
DEF & definite determiner & Q & quantifier \\
DEM & demonstrative & SG & singular \\
DET & determiner & TOP & topic
\end{tabular}

Throughout I use standard Malagasy orthography—note that the apostrophe and the hyphen are orthographic conventions that occur, for example, in instances of genitive case.

${ }^{3}$ It is important to note that $n y$ is compatible with definiteness (speakers often translate examples of $n y$ with a definite determiner in French or English), but it does not always encode definiteness, as will be shown in detail throughout this article.

${ }^{4}$ Note that in the second clause of (2) the subject is a thematic objectpromoted to subject via voice alternations. As has been long noted in the literature, however, so-called voice in Malagasy is not the same as English passive and therefore the translations remain active. Keenan and Manorohanta (2001) show that in text counts, active and passive are 
equally prevalent. Pearson (2005) argues that the subject position is an Abar position. Rasolofo (2006) claims that the passive is an inverse construction and is used to signal the increased topicality of the thematic object. In (2), however, it is not clear in what sense ny hazo 'a tree' is topical.

5 Zribi-Hertz and Mbolatianavalona (1999:186) claim that the definite determiner $n y$ is barred from the object position (unless required to license a modifier). They propose that there is a null determiner that is in complementary distribution with $n y$. I have never worked with a speaker with this restriction; nevertheless I, too, will argue for null determiners.

${ }^{6}$ Kehler and Ward (2006) look at the English data from a slightly different perspective and claim that the failure to use a definite noun phrase (e.g., the use of a dog over the $d o g$ ) conversationally implicates nonfamiliarity.

${ }^{7}$ It might be possible to conflate (18a) and (18c) as both being instances of a bare nominal in an accusative case position.

${ }^{8}$ Note that this conclusion conflicts with Gillon (2006, this volume). As we will see, bare nominals do not introduce domain restriction, therefore, according to Gillon, they lack D. The existence of a null determiner is not crucial to the present analysis and perhaps more evidence could be found for or against such an element. 
${ }^{9}$ Bare verbs in Malagasy typically take the theme as an external argument (i.e., they are like Theme Topic marked verbs but without the voice morphology).

${ }^{10}$ There are some exceptions to this, but overwhelmingly the complement of amin occurs with a determiner/demonstrative. This is likely related to case: the complement of amin is in the genitive case and, as Keenan (to appear) points out, text counts show that $94 \%$ of genitives are formally definite.

The reader will also note that the preposition amin is preceded by the locative element teo 'there'. Most instances of locatives in Malagasy involve both a locative element and a preposition-we will see further examples in (36)-(38).

${ }^{11}$ Rasolofo's (2006) text-count analysis of narratives shows that $36 \%$ of DP objects are of low topicality: the antecedent to the referent occurs four or more clauses back in the text. I do not know if she found any truly nonfamiliar uses of DP objects, however, nor do I have examples that illustrate her "low topical" DPs. A complicating factor is the use of nonactive verbal forms and hence the low numbers of object DPs overall.

${ }^{12}$ The DP in (31) is interpreted as partitive without being overtly partitive. To express partitivity, Malagasy uses a complex structure with a preposition (much like English):

(i) iray amin'ny akondro 


\footnotetext{
one P DET banana

'one of the bananas'

${ }^{13}$ Example (32) may in fact be an instance of a non-familiar DP object.

Given the context of the utterance, however (a discussion about money concerns), this could be an example of a "bridging definite".

${ }^{14}$ I call anaty 'in' a preposition, but it is in fact morphologically complex, made up of the preposition an and the noun aty 'the interior'. The category of $a n$ is also not clear. It surfaces between locative elements like eny 'there', eo 'here' and their complement and also productively creates locatives (e.g., havia 'left' $\rightarrow$ ankavia 'to/on the left'). Abinal and Malzac (1888) list it as a preposition and compare it with amin, another allpurpose preposition; Dez (1980) follows this classification and claims that there are only two prepositions in Malagasy: amin and an. Given that an creates manner adverbs (e.g., tselika 'nimble' $\rightarrow$ antselika 'nimbly'), it seems reasonable to classify it as a preposition.

${ }^{15}$ Here we have the reverse image of the preposition amin: anaty is overwhelmingly followed by a bare nominal, but a DP complement is also possible.

${ }^{16}$ In the context of the story, lalomena means a large beast. In my dictionary (Abinal and Malzac 1888), the definition is "extinct pygmy hippopotamus".
} 
${ }^{17}$ An anonymous reviewer asks if these examples of bare nominals are similar to the English bare definites (e.g., in hospital) (see section 7.1). The textual examples I have found show a range of nouns (house, water, forest, bridge, car), which suggests that the Malagasy examples are different. Moreover, elicited data show that any noun that is the complement of anaty can be interpreted as familiar (see for example (40)).

${ }^{18}$ Rasolofo (2006) examines the topic continuity of arguments in Malagasy folk tales and in elicited texts, and shows that in sentences where the object is a bare nominal, the referent has been previously mentioned (i.e., is familiar) in $18 \%$ of the instances. While much lower than newly introduced (non-familiar) uses of bare nominals, these results appear to show that bare nominals can be familiar. I found the following passage from one of the stories analyzed by Rasolofo: 
(i) Rehefa tonga teo amin'io anana maitso mavana sy when arrive there $P$ this plant green splendid and maha te-hihinana io ny lakana, niteny tamin'ny cause want-eat this DET canoe PST.AT.say PST.P DET mpivoy i Damo hijanona kely paddler DET Damo FUT.AT.stop little hitsongo anana.

FUT.AT.gather plant

'When the canoe arrived close to this green and appetizing edible plant, Damo ordered the paddlers to stop a minute to gather some.' (Ravololomanga 1996:18)

Here the second mention of anana 'plant' is a bare nominal, but is clearly familiar and receives a partitive reading - they will gather some of the plant. On the other hand, native speaker consultants routinely reject bare nominals in familiar contexts. I therefore take (i) to be an exception. Clearly more research is required.

${ }^{19}$ David Heap (p.c.) points out that Martinet (1968) discusses similar effects on the meaning of the French subjunctive-what is called "la servitude grammaticale". Roughly, when the subjunctive is selected (e.g., by a matrix verb), there is no special meaning associated with it. But when it is optional (e.g., in relative clauses), the choice between the subjunctive and the indicative has interpretative consequences. 
(i) Je cherche quelqu'un qui sait le français. (indicative = referential)

(ii) Je cherche quelqu'un qui sache le français (subjunctive = nonreferential)

'I'm looking for someone who speaks French.'

\section{References}

Abinal, R.P. \& S.J. Malzac. 1888. Dictionnaire malgache-français. Fianarantsoa, Madagascar.

Adger, D. 1996. Economy and optionality: Interpretation of subjects in Italian. Probus 8:117-135.

Carlson, G. \& R. Sussman. 2005. Seemingly indefinite definites. In Linguistic Evidence: Empirical, Theoretical, and Computational Perspectives, S. Kesper \& M. Reis (eds), 71-85. Berlin: Mouton de Gruyter.

Contreras, H. 1986. Spanish bare NPs and the ECP. In Generative Studies in Spanish Syntax, I. Bordelois, H. Contreras \& K. Zagona (eds), 2549. Dordrecht: Foris.

Dahl, O.C. 1951. Malgache et Maanjan.. Egede-Instituttet. Oslo

Dez, J. 1980. La syntaxe du malgache. Thèse de doctorat, Université de Paris VII. Lille: Atelier reproduction des thèses.

Dez, J. 1990. Cheminements linguistiques malgaches. Paris: Peeters/SELAF. 
Domenichini-Ramiaramanana, B. 1977. Le malgache. Essai de description sommaire. Paris: SELAF.

von Fintel, K. 1999. Quantifier domains and pseudo-scope. Ms., Massachusetts Institute of Technology.

Fugier, H. 1999. Syntaxe malgache. Louvain-la-Neuve: Peeters.

Gillon, C. 2006. The semantics of determiners: Domain restriction in Skwwxúf $7 m e s h$. PhD thesis, University of British Columbia.

Gillon, C. This volume. The semantic core of determiners: Evidence from Skwxwú7mesh.

Jedele, T. \& L. Randrianarivelo. 1998. Malagasy Newspaper Reader. Kensington, MD: Dunwoody Press.

Keenan, E. 1976. Remarkable subjects in Malagasy. In Subject and Topic, C. Li (ed), 249-301. New York: Academic Press.

Keenan, E. 2007. Quantification in Malagasy. In Quantification: A Crosslinguistic Perspective, L. Matthewson (ed), 319-352. Amsterdam: John Benjamins.

Keenan, E. 2008. The definiteness of subjects and objects in Malagasy. In Case and Grammatical Relations, G. Corbett \& M. Noonan (eds), 241-261. Amsterdam: John Benjamins.

Keenan, E. and B. Ralalaoherivony. 2000. Raising from NP in Malagasy. Lingvisticae Investigationes 23:1-44. 
Keenan, E. \& C. Manorohanta. 2001. A quantitative study of voice in Malagasy. Oceanic Linguistics 40:67-85.

Kehler, A. \& G. Ward. 2006. Referring expressions and conversational implicature. In Drawing the Boundaries of Meaning, B. Birner \& G. Ward (eds), 177-194. Amsterdam, John Benjamins.

Landau, I. 2007. EPP extensions. Linguistic Inquiry 38:485-523.

Law, P. 2006. Argument-marking and the distribution of wh-phrases in Malagasy, Tagalog and Tsou. Oceanic Linguistics 45:153-190.

Lyons, C. 1999. Definiteness. Cambridge: Cambridge University Press.

Martinet, A. 1968. Neutralisation et syncrétisme. La linguistique 1:1-20.

Massam, D., C. Gorrie \& A. Kellner. 2006. Niuean determiners:

Everywhere and nowhere. In Proceedings of the 2006 annual conference of the Canadian Linguistic Association, C. Gurski \& M. Radisic (eds), 16 pages. http://ling.uwo.ca/publications/CLA2006/Massam.pdf

Mathieu, E. This volume. From local blocking to cyclic agree: The role and meaning of determiners in the history of French

Matthewson, L. 1998. Determiner Systems and Quantificational Strategies: Evidence from Salish. The Hague: Holland Academic Graphics.

Ntelitheos, D. 2006. The Morpho-Syntax of Nominalizations: A Case Study. PhD thesis, University of California, Los Angeles. 
Paul, I. 2001. Concealed pseudo-clefts. Lingua 111:707-727.

Paul, I. 2009. External possession meets bare nouns in Malagasy. Lingua 119:224-241.

Pearson, M. 2005. The Malagasy subject/topic as an A-bar element. Natural Language and Linguistic Theory 23:381-457.

Prince, E.F. 1981. On the inferencing of indefinite-this NPs. In Elements of Discourse Understanding, A.K. Joshi, B.L. Webber, \& I.A. Sag (eds), 231-250. Cambridge: Cambridge University Press.

Rajaobelina, P. 1960. Gramera malagasy. Tananarive: Trano Printy Loterana.

Rackowski, A. 1998. Malagasy adverbs. In The Structure of Malagasy, Vol. 2, I. Paul (ed), 11-33. Los Angeles: University of California, Los Angeles.

Rackowski, A. \& L. Travis. 2000. V-initial languages: X or XP movement and adverbial placement. In The Syntax of Verb Initial Languages, A. Carnie \& E. Guilfoyle (eds), 117-142. Oxford: Oxford University Press.

Rahajarizafy, A. 1960. Essai de grammaire malgache. Antanimena Tananarive: Imprimerie Catholique.

Rajaona, S. 1972. Structure du malgache: Etude des formes prédicatives. Fianarantsoa, Madagascar: Librairie Ambozontany. 
Rajemisa-Raolison, R. 1971. Grammaire malgache. Fianarantsoa, Madagascar: Librairie Ambozontany.

Rasolofo, A. 2006. Malagasy transitive clause types and their functions. Ph.D. thesis, University of Oregon.

Ravololomanga, B. 1996. Le lac bleu et autres contes de Madagascar. Paris: L'Harmattan.

Stvan, L. 1998. The semantics and pragmatics of bare singular noun phrases. $\mathrm{PhD}$ dissertation, Northwestern University.

Westerståhl, D. 1984. Determiners and context sets. In Generalized Quantifiers in Natural Languages, J. van Bentham \& A. ter Meulen (eds), 45-71. Dordrecht: Foris.

Williams, E. 1997. Blocking and anaphora. Linguistic Inquiry 28:577628.

Zribi-Hertz, A. \& L. Mbolatianavalona. 1999. Towards a modular theory of linguistic deficiency: Evidence from Malagasy personal pronouns. Natural Language and Linguistic Theory 17:161-218. 